\title{
On the Influence of Tribological Properties of AISI 4140 Annealed Steel against Ceramic Counterparts under Dry and Lubricated Conditions and Their Effect on Steel Microstructure
}

\author{
Luis D. Aguilera-Camacho ${ }^{1}{ }^{\mathbb{D}}$, María T. Hernández-Sierra ${ }^{1,2}{ }^{\mathbb{D}}$, J. Santos García-Miranda ${ }^{1}$ \\ and Karla J. Moreno ${ }^{1, *(\mathbb{D})}$
}

1 Department of Mechanical Engineering, National Technology of Mexico in Celaya (TecNM), Celaya 38010, Mexico; daniel.ac@celaya.tecnm.mx (L.D.A.-C.); teresa.hernandez@itcelaya.edu.mx (M.T.H.-S.); santos.gm@celaya.tecnm.mx (J.S.G.-M.)

2 Department of Chemistry, University of Guanajuato, Guanajuato 36050, Mexico

* Correspondence: karla.mb@celaya.tecnm.mx; Tel.: +52-461-611-7575

Citation: Aguilera-Camacho, L.D.; Hernández-Sierra, M.T.; García-Miranda, J.S.; Moreno, K.J. On the Influence of Tribological Properties of AISI 4140 Annealed Steel against Ceramic Counterparts under Dry and Lubricated Conditions and Their Effect on Steel Microstructure. Metals 2021, 11, 1275. https://doi.org/10.3390/ met11081275

Academic Editor: Zhengyi Jiang

Received: 14 July 2021

Accepted: 10 August 2021

Published: 12 August 2021

Publisher's Note: MDPI stays neutral with regard to jurisdictional claims in published maps and institutional affiliations.

Copyright: (c) 2021 by the authors. Licensee MDPI, Basel, Switzerland. This article is an open access article distributed under the terms and conditions of the Creative Commons Attribution (CC BY) license (https:/ / creativecommons.org/licenses/by/ $4.0 /)$.

\begin{abstract}
AISI 4140 steel is still one of the most distinguished steels employed in tribological applications because of its low cost, great mechanical properties, and appropriate wear resistance. In this contribution, the tribological performance of AISI 4140 annealed steel against engineering ceramic was analyzed to promote parameters for the application of this steel, especially in systems that are subjected to contact pressures between 490-1240 MPa. Dry and lubricated pin-on-disk experiments were completed at different normal loads. The worn surfaces were analyzed by contact profilometry, optical and scanning electron microscopies, energy dispersive spectroscopy, and microhardness examinations. In dry conditions, a better friction response was found on the steel tested with $\mathrm{ZrO}_{2}$. Friction coefficient and wear rate resulted in reductions up to $60 \%$ and $99 \%$ compared with those obtained with $\mathrm{Al}_{2} \mathrm{O}_{3}$ and $\mathrm{Si}_{3} \mathrm{~N}_{4}$ counterparts. A strain-hardening phenomenon due to the friction process was observed on the samples tested with $\mathrm{ZrO}_{2}$ and $\mathrm{Si}_{3} \mathrm{~N}_{4}$, which showed grain refinement and hardness increment on worn surfaces. Therefore, those systems exhibited better wear responses. In lubricated conditions, all counterparts exhibited low friction and wear, but the performance of $\mathrm{Al}_{2} \mathrm{O}_{3}$ and $\mathrm{Si}_{3} \mathrm{~N}_{4}$ was highlighted. The results demonstrate that the performance of AISI 4140 annealed steel under the tested conditions is comparable with that of the same steel with other surface treatments.
\end{abstract}

Keywords: AISI 4140 steel; $\mathrm{ZrO}_{2} ; \mathrm{Al}_{2} \mathrm{O}_{3} ; \mathrm{Si}_{3} \mathrm{~N}_{4}$; tribology; sliding friction; wear; lubrication

\section{Introduction}

AISI 4140 steel continues to receive much attention in applications as a mechanical component in the metal-mechanic industry. Several authors have described it as a "ubiquitous material" because of its extensive use in the automotive, aerospace, and manufacturing sector [1-3]. The content of elements such as Molybdenum (0.15-0.25 wt.\%), Chromium (0.80-1.10 wt.\%), and Manganese (0.75-1.00 wt.\%) provides this low-alloy steel with great properties. Depending on the microstructure and hardness, the AISI 4140 steel is commonly employed for various applications such as frames, support tools, crankshafts, tools joints, connecting rods, gear, pump, sprockets, tool holders, etc. [4,5]. Moreover, it is a very attractive material for studies on surface modification to enhance, particularly, its hardness and wear performance for specific applications. These modifications include a wide variety of following methods that have an essential impact on the cost and time of the workpiece or mechanical parts' manufacturing. Such changes in the steel involve thermochemical treatments, plasma nitriding, plasma oxynitride, nitrocarburizing and boronizing processes; even until hard coatings deposition [1,3-6]. Although the annealing condition of AISI 4140 steel is represented by lower mechanical strength with higher plastic 
energy and ductility than the same material exposed to other thermal treatments $[7,8]$, it has been demonstrated that this state involves significant improvements in the low-cycle fatigue behavior [7], and on its wear resistance [8].

On the other hand, ceramic materials have become increasingly important for designing wear-resistant components due to their superior hardness, null chemical reaction, high melting point, as well as their distinguished anti-wear and anti-friction performance [9-13]. Additionally, ceramics can maintain their high hardness and strength at extreme temperatures [14]. Ceramics employed in this kind of application generally involve oxides, nitrides, or carbides of metals such as aluminum, silicon, and others [14]. Silicon nitride $\left(\mathrm{Si}_{3} \mathrm{~N}_{4}\right)$, Zirconium oxide $\left(\mathrm{ZrO}_{2}\right)$, and Aluminum oxide $\left(\mathrm{Al}_{2} \mathrm{O}_{3}\right)$ ceramics have been proposed as mechanical pairs in hydraulic systems [9], whereas $\mathrm{ZrO}_{2}$ and $\mathrm{Al}_{2} \mathrm{O}_{3}$ have been used in applications for the drilling industry [10].

The present study focused on investigating the tribological performance of AISI 4140 annealed steel against three different ceramics counterparts, Zirconium oxide $\left(\mathrm{ZrO}_{2}\right)$, Aluminum oxide $\left(\mathrm{Al}_{2} \mathrm{O}_{3}\right)$, and Silicon nitride $\left(\mathrm{Si}_{3} \mathrm{~N}_{4}\right)$, in order to spread the applications of AISI 4140 annealed steel and to contribute with the understanding of these ceramic counterparts as friction pairs. Besides, the idea to consider the annealed condition is to contribute to sustainability based on green tribology which, in addition to various other considerations, encourages the use of materials that do not require several processes but possess desirable strength-low-cost characteristics. For that purpose, sliding friction tests were conducted under dry and wet conditions applying three different loads. Additionally, the influence of wear performance on the surface properties of AISI 4140 annealed steel was analyzed by microhardness indentation.

\section{Materials and Methods}

\subsection{Disk and Pin Materials}

In this research, commercial AISI 4140 steel in annealed condition was used for the manufacturing of the disks, and no additional surface or thermal treatments were applied. Table 1 includes the chemical composition range of the steel according to the supplier information. Disk samples of $5 \mathrm{~mm}$ in thickness were cut from a $12.7 \mathrm{~mm}$ radius cylindrical steel bar and polished to an average surface roughness of $\mathrm{Ra}=0.04 \mu \mathrm{m}$. Commercial balls of Zirconium dioxide with Yttria Stabilized Zirconia (YSZ) phase (in the following named as $\left.\mathrm{ZrO}_{2}\right)$, Aluminum trioxide $\left(\mathrm{Al}_{2} \mathrm{O}_{3}\right)$, and Silicon nitride $\left(\mathrm{Si}_{3} \mathrm{~N}_{4}\right)$ were employed as counterpart materials since they have great potential for use in tribological contacts. The radius and surface roughness of balls were $3 \mathrm{~mm}$ and $\mathrm{Ra}=0.03 \mu \mathrm{m}$, respectively. A Mitutoyo profilometer Surftester 402 was used to determine the Ra parameter of the samples. Table 2 shows the mechanical properties of the disk and counterpart materials.

Table 1. Chemical composition of the AISI 4140 annealed steel.

\begin{tabular}{|c|c|c|c|c|c|c|c|}
\hline$\% \mathrm{C}$ & $\% M n$ & $\% \mathrm{Cr}$ & \%Mo & $\% S i$ & $\% P$ & $\% S$ & $\% \mathrm{Fe}$ \\
\hline $0.38-0.43$ & $0.76-1.00$ & $0.80-1.10$ & $0.15-0.25$ & $0.15-0.35$ & 0.035 max. & 0.04 max. & Balance \\
\hline
\end{tabular}

Table 2. Mechanical properties of the disk and counterpart materials.

\begin{tabular}{|c|c|c|c|c|c|}
\hline Material & $\begin{array}{c}\text { Vickers } \\
\text { Micro- } \\
\text { Hardness (GPa) }^{\text {a }}\end{array}$ & $\begin{array}{l}\text { Tensile Strength } \\
\text { Ultimate (MPa) }\end{array}$ & $\begin{array}{c}\text { Fracture } \\
\text { Toughness } \\
\left(\mathrm{MPa.m}^{1 / 2}\right)^{\mathrm{b}}\end{array}$ & $\begin{array}{c}\text { Modulus of } \\
\text { Elasticity (GPa) }\end{array}$ & $\begin{array}{l}\text { Poisson's } \\
\text { Ratio, } v^{b}\end{array}$ \\
\hline AISI 4140 & $2.08-2.16$ & 850-1000 & $117-123$ & 210 & 0.27 \\
\hline $\mathrm{ZrO}_{2}$ & $12.43-12.93$ & $200-350$ & 7-13 & 200 & $0.23-0.3$ \\
\hline $\mathrm{Al}_{2} \mathrm{O}_{3}$ & $20.65-21.49$ & $200-300$ & $2-3$ & $300-400$ & $0.23-0.25$ \\
\hline $\mathrm{Si}_{3} \mathrm{~N}_{4}$ & $13.22-13.22$ & $200-350$ & $3.5-5$ & $280-310$ & $0.21-0.25$ \\
\hline
\end{tabular}

${ }^{a}$ Average value obtained in this study. ${ }^{\text {b }}$ Standard supplier literature value. 


\subsection{Microstructure Characterization of the AISI 4140 Annealed Steel}

The microstructure of the steel material was revealed by its chemical etching with Nital's reagent $\left(2 \mathrm{~mL} \mathrm{HNO}_{3}\right.$ and $98 \mathrm{~mL}$ ethanol). After the etching, the surface was studied by using an optical microscope Carl Zeiss Axio Image (Zeiss, Oberkochen, Germany), whereas the phase determination was analyzed by a PANalytical Empyrean (Malvern Panalytical, Malvern, United Kingdom) X-ray diffractometer equipment (radiation of $\mathrm{CuK}_{\alpha}$, $\lambda=1.5406 \AA$ ). Additionally, the grain size was determined by the Planimetric Procedure recommended in ASTM E 112-12 standard, and the volume fraction of constituents was determined according to the ASTM E 562-02 using a square grid.

\subsection{Friction and Wear Investigation}

Friction experiments were carried out by the pin-on-disk method in a Standard Tribometer (TRB) of CSM Instruments Company (Needham, MA, USA). All tests were fixed to the following conditions: room temperature of $25^{\circ} \mathrm{C}$, a total sliding distance of $1000 \mathrm{~m}$, a radius of wear track of $2 \mathrm{~mm}$, and normal loads of $1.5,3$, and $5 \mathrm{~N}$. Table 3 gives the corresponding contact pressures for each ball on the steel flat surface, which were determined from the Hertz contact theory. On the other hand, the employed relative sliding speeds were $0.1 \mathrm{~ms}^{-1}$ for dry and $0.05 \mathrm{~ms}^{-1}$ for lubricated tests. The lubricated tests were carried out by employing $20 \mathrm{~mL}$ of a commercial mineral base oil, which is used as a lubricant in the manufacturing process. This lubricant was previously characterized in [15], where its performance was compared against that of pure castor oil.

Table 3. Mean $\left(\mathrm{p}_{\mathrm{m}}\right)$ and maximum ( $\left.\mathrm{p}_{\max }\right)$ contact pressures obtained under different conditions.

\begin{tabular}{|c|c|c|c|c|c|c|}
\hline \multirow{3}{*}{ Counterpart } & \multicolumn{6}{|c|}{ Hertz Contact Pressure (MPa) } \\
\hline & \multicolumn{2}{|c|}{$1.5 \mathrm{~N}$} & \multicolumn{2}{|c|}{$3 \mathbf{N}$} & \multicolumn{2}{|c|}{$5 \mathrm{~N}$} \\
\hline & $\mathrm{p}_{\mathrm{m}}$ & $p_{\max }$ & $\mathrm{p}_{\mathrm{m}}$ & $p_{\max }$ & $\mathrm{p}_{\mathrm{m}}$ & $p_{\max }$ \\
\hline $\mathrm{ZrO}_{2}$ & 490 & 730 & 610 & 920 & 720 & 1090 \\
\hline $\mathrm{Al}_{2} \mathrm{O}_{3}$ & 550 & 830 & 690 & 1040 & 820 & 1230 \\
\hline $\mathrm{Si}_{3} \mathrm{~N}_{4}$ & 550 & 830 & 700 & 1050 & 830 & 1240 \\
\hline
\end{tabular}

The kinetic friction coefficients $\left(\mu_{\mathrm{k}}\right)$ were obtained directly from the Tribox $4.5 \mathrm{R}$ software (accessed on 10 February 2015). Five measurements of friction were tested to assess the repeatability; thus, the presented results are the average of the five readings. Steel worn surfaces were investigated by using a scanning electron microscope JEOL JSM6510LV (JEOL Ltd., Tokyo, Japan) connected with an energy-dispersive X-ray detector. The wear of the pin pair was negligible compared to the wear of the steel disk in all the examinations; therefore, the pin pair wear was ignored in this study. The volume loss (V) was calculated by using a metrological technique, as suggested in [16]. Wear track profiles were obtained by contact profilometry with the equipment commented on Section 2.1 at several regions of the wear track on the disk material, as shown in Figure 1a (direction of the profile lectures). The volume loss (V) was evaluated by integrating the wear track profile to obtain the cross-section area of the wear track (Awt) by using data analysis and graphics software OriginPro 8 Figure $1 \mathrm{~b}$ ), and by multiplying this value by the average track length $(\mathrm{L})$. The wear track area represents the real cross-section area of the material that was removed from the original surface. Considering that $L=2 \pi R$ and $R$ is the wear track radius, $\mathrm{V}$ can be determined from Equation (1):

$$
\mathrm{V}=\mathrm{Awt} \times \mathrm{L}
$$




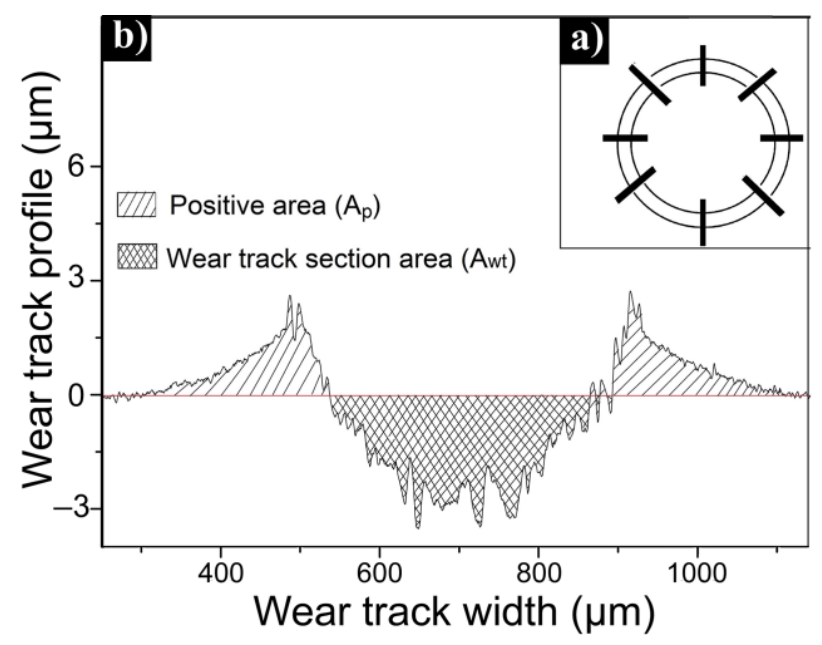

Figure 1. Schematization for readings of wear track profiles obtained (a) and calculations of the wear track section area (Awt) (b).

Wear rate (K) was calculated from Equation (2), where $\mathrm{F}$ is the applied normal load and $\mathrm{S}$ is the sliding distance.

$$
\mathrm{K}=\mathrm{V} / \mathrm{FS}
$$

To compare the friction and wear performance of AISI 4140 annealed steel with that of the hardened and tempered steel, additional tests were carried out using the $\mathrm{ZrO}_{2}$ counterpart under the same tribological conditions at $5 \mathrm{~N}$ and without lubrication. For this purpose, AISI 4140 annealed steel disk samples were austenitized in a muffle furnace Barnstead International 48,000 (Thermo Fisher Scientific, Waltham, MA, USA) at a temperature of $855^{\circ} \mathrm{C}$ for $15 \mathrm{~min}$; consecutively, samples were quenched in commercial engine oil. As soon as the quenching procedure was completed, the samples were tempered in another furnace at a temperature of $425^{\circ} \mathrm{C}$ for $15 \mathrm{~min}$ to achieve a hardness value of 45 HRC (Vickers hardness of $5.18 \mathrm{GPa}$ ). Then, the hardened and tempered steel samples were allowed to cool in standard air until reaching room temperature. After this procedure, the Rockwell hardness was measured in a Hardness Tester TH722 from Time Group, Inc. (TIME Group, Inc., Beijing, China), while the microstructure was revealed following the procedure described in Section 2.2. Additionally, the samples were metallographically prepared to achieve the surface roughness that was fixed for the tribological evaluations $(0.04 \mu \mathrm{m}$ in $\mathrm{Ra})$.

\subsection{Microhardness Measurements}

To analyze the influence of the wear performance on the mechanical surface properties modification of AISI 4140, the microhardness was measured by using a Microhardness Tester (SMVK-1000ZS) from Metrotec (Metrotec, Lezo, Spain) with a load of $9.81 \mathrm{~N}$ for $15 \mathrm{~s}$. Ten measurements were taken before and after wear tests, these were obtained at $500 \mathrm{~m}$ and $1000 \mathrm{~m}$ of sliding distance in different points within the wear track.

\subsection{Lubrication Regime Estimation}

In order to define the lubrication regime in which the tribosystems operated, the film thickness ratio $(\lambda)$ was determined. It is well established that boundary lubrication exists when $\lambda$ is lesser than 1 , mixed lubrication when $\lambda$ ranges from 1 to 3 , and hydrodynamic/elastohydrodynamic lubrication when $\lambda$ is higher than 3 . This parameter is given by Equation (3) where $h$ is lubricant film thickness and $\sigma^{*}$ is the composite surface roughness.

$$
\lambda=\mathrm{h} / \sigma^{*}
$$


In this work, based on the theory of Hamrock and Dowson [17], the lubricant film thicknesses were determined following the methodology described in [18].

\section{Results}

\subsection{Microstructure of the AISI 4140 Annealed Steel}

Figure 2a exhibits the typical microstructure of the AISI 4140 annealed steel. It can be observed that the optical micrograph displays coarse pearlite and ferrite phases, whereas its $X$-ray diffraction pattern (Figure 2b) shows only the phase $\alpha$-Fe by the PAN-ICSD code from the PANalytical database. The mean grain size of the ferrite and pearlite phases were $26 \pm 7$ and $42 \pm 15 \mu \mathrm{m}$, respectively, and the average of them was $33 \pm 14 \mu \mathrm{m}$. The number of grains by $\mathrm{mm}^{2}$ at $500 \mathrm{X}$ was $1214.3 \pm 62$ and the average grain area was $0.00082 \pm 0.00005 \mathrm{~mm}^{2}$. Approximately, it corresponds to a grain size number (G) of $7 \pm 5$ agreeing with the ASTM E 112-12. On the other hand, in accordance with the ASTM E 562-02 standard, approximately $40 \%$ of the steel is in the ferrite phase, while the other $60 \%$ is found as coarse pearlite.
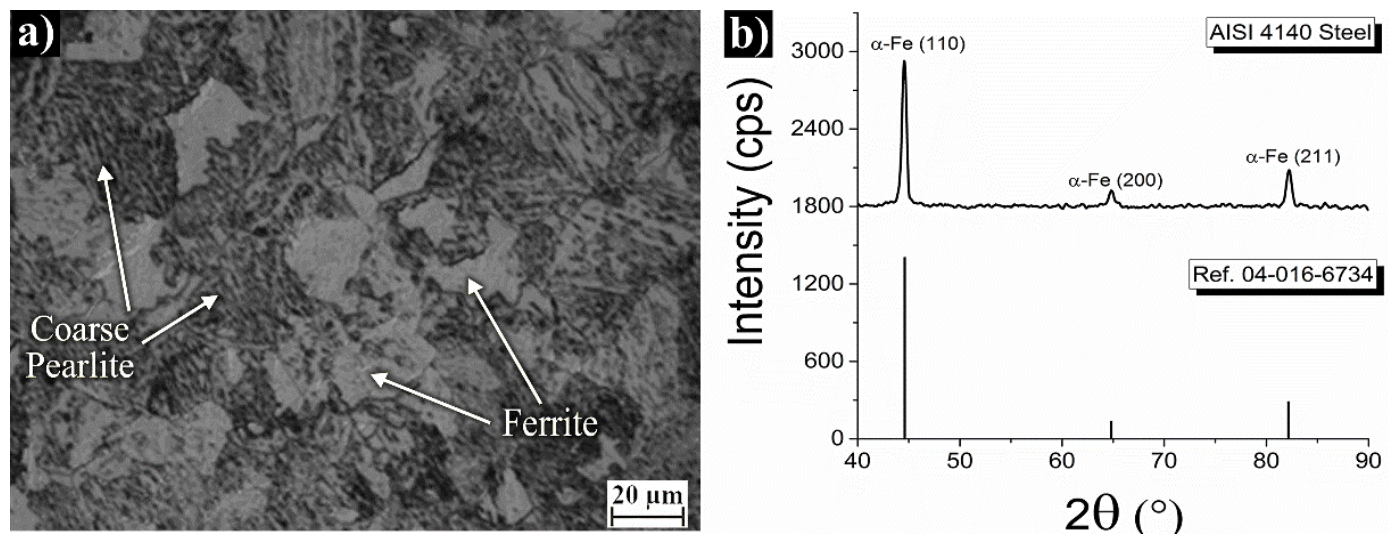

Figure 2. Characteristic microstructure of AISI 4140 annealed steel: optical micrograph at 500X of etched surface (a) and XRD pattern (b).

\subsection{Tribological Behavior of AISI 4140 Annealed Steel against Ceramics in Dry Conditions \\ 3.2.1. Friction Behavior}

The effect of different ceramic counterparts and normal loads on the mean kinetic friction coefficient of the AISI 4140 annealed steel for dry conditions is shown in Figure 3. It can be observed in Figure 3 that AISI 4140 annealed steel tested with $\mathrm{ZrO}_{2}$ as counterpart exhibited the lowest friction coefficient values under the three employed normal loads. The friction coefficient values varied from 0.38 to 0.55 , whereas the highest friction values were found when the steel was tested against $\mathrm{Si}_{3} \mathrm{~N}_{4}$; here the kinetic friction coefficient ranged from 0.92 to 0.71 . A clear tendency to increase the friction coefficient with the growth of normal load was observed in systems tested against $\mathrm{ZrO}_{2}$ and $\mathrm{Al}_{2} \mathrm{O}_{3}$. However, the opposite behavior was exhibited with the $\mathrm{Si}_{3} \mathrm{~N}_{4}$ counterpart. The variation in the friction coefficient with increasing load was much lower in the system tested against alumina, where in all cases the friction coefficients were closed to 0.56 . 


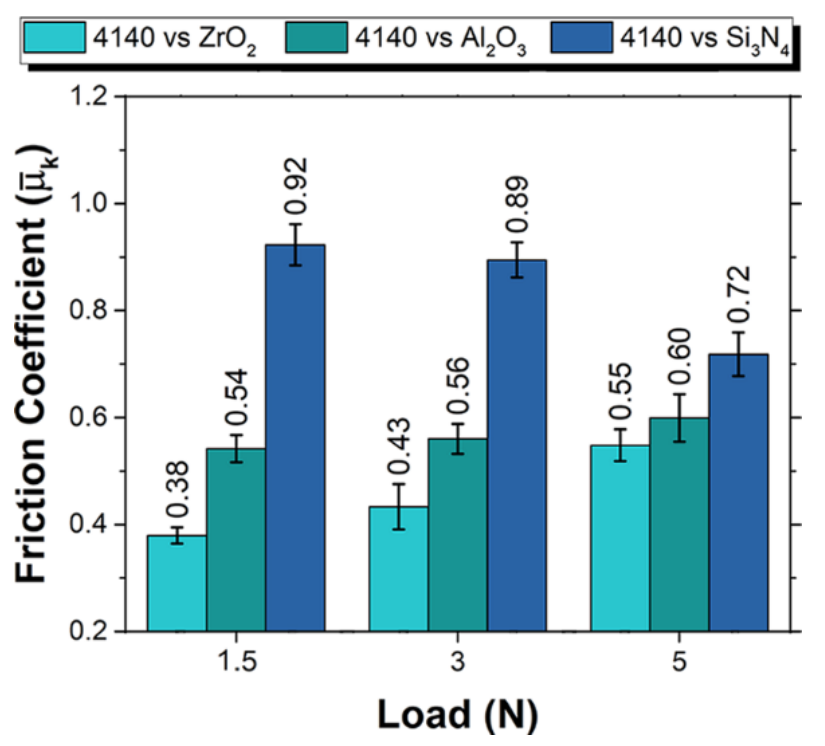

Figure 3. Effect of counterparts and loads on the friction performance of AISI 4140 annealed steel in dry conditions.

\subsubsection{Wear Mechanisms}

Figure 4 shows representative micrographs of the wear track region on AISI 4140 annealed steel examined at $5 \mathrm{~N}$, as well as the wear profiles of the systems. Under the tested conditions, it was observed that the wear mechanism exhibited by AISI 4140 annealed steel in dry conditions depended heavily on the counterpart employed, but not on the load. It is well established that friction and wear are very complex phenomena that are highly dependent on all the tribosystem conditions $[19,20]$. Even worn surfaces generally wear out by more than one process concurrently or one after another. It can be seen in Figure $4 \mathrm{a}$ that, when AISI 4140 annealed steel was tested against $\mathrm{ZrO}_{2}$, it presented a combination of abrasive and adhesive wear modes, which led it to generate wear marks with little depth and width, as can be confirmed by the wear profiles (Figure $4 \mathrm{~d}$ ). The $\mathrm{Al}_{2} \mathrm{O}_{3}$ counterpart produced the wear of the steel mainly by abrasion; see Figure $4 \mathrm{~b}$,e. The material removed from the contacting surface generated deeper wear tracks and pile-up material stacking at the ends of the track. On the other hand, steel samples tested against $\mathrm{Si}_{3} \mathrm{~N}_{4}$ showed common signs of abrasive and adhesive wear (Figure $4 \mathrm{c}, \mathrm{f})$. The wear profiles showed some grooves due to abrasive wear; some of the material was trapped inside the wear track and some was piled up at the ends. In all systems, it was observed that as the load increased, the width and profundity of the wear tracks, including the amount of pile-up material, increased. Figure S1 in the Supplementary Materials file shows optical micrographs of AISI 4140 annealed steel worn surfaces at all loads.

For in-depth analysis of the wear of the steel, Figure 5 shows SEM images and EDS spectra for AISI 4140 annealed steel worn surfaces tested at $5 \mathrm{~N}$ with the three different ceramic counterparts as representative samples. It can be observed in Figure 5a that the steel sample tested against $\mathrm{ZrO}_{2}$ displayed some furrows as well as some bumps of adhering material. As stated in [19], adhesion typically arises at the joints of rough edges, then, plastic shearing of the softest asperities occurs; in this case, the AISI 4140 annealed steel, releasing particles that adhere to the counterface. However, as sliding continues, the transferred particles dislodge from the pin surface and adhere again to the steel. Such processes can create larger and harder particles that can end up adhered to the surface, or free between contact, thus producing abrasive wear, as can be observed in Figure $5 \mathrm{a}$. Nevertheless, when analyzing the region marked with number 1 through EDS (Figure 5d), the presence of oxygen was observed, which could imply oxidation of the steel. 

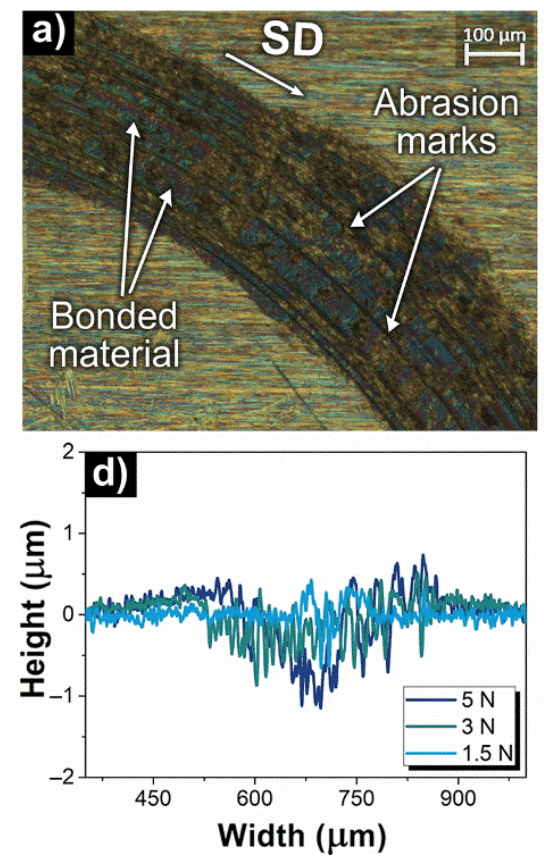
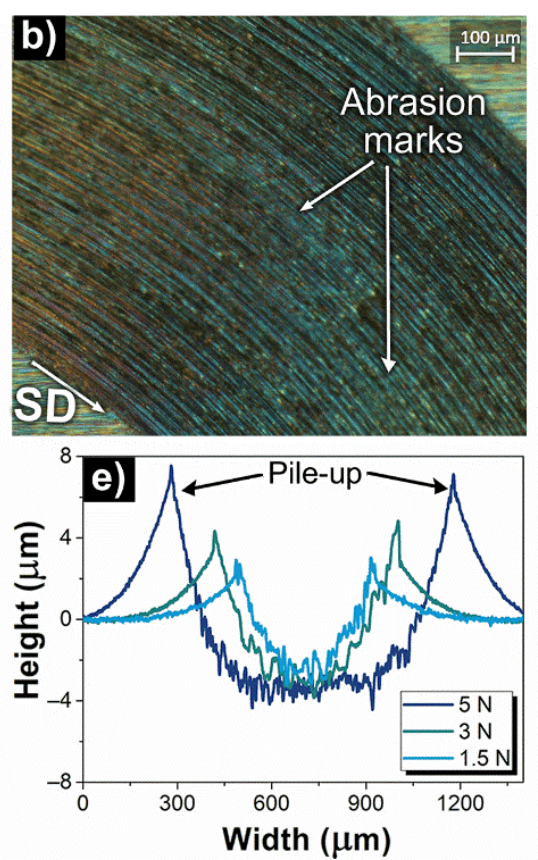
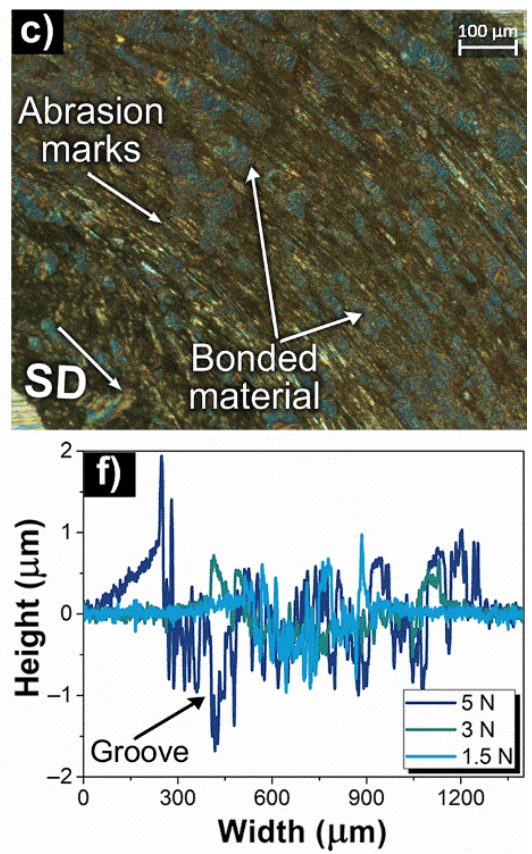

Figure 4. The optical micrographs and profiles of the wear mark on AISI 4140 annealed steel tested in dry conditions with different ceramic counterparts: $\mathrm{ZrO}_{2}(\mathbf{a}, \mathbf{d}), \mathrm{Al}_{2} \mathrm{O}_{3}(\mathbf{b}, \mathbf{e})$, and $\mathrm{Si}_{3} \mathrm{~N}_{4}(\mathbf{c}, \mathbf{f})$. Note: The optical micrographs were taken at $100 \mathrm{X}$ with a polarizing filter and correspond to the load of $5 \mathrm{~N}$ as representative samples. SD represents the sliding direction of the friction tests.

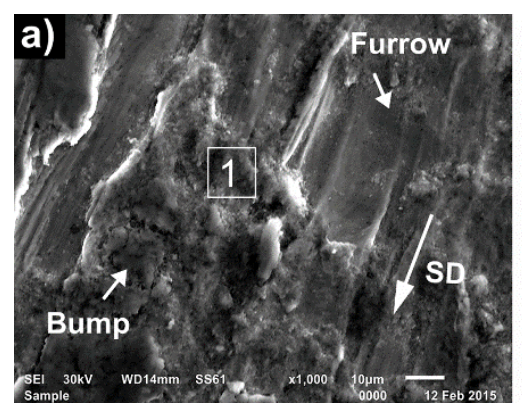

\section{d)}

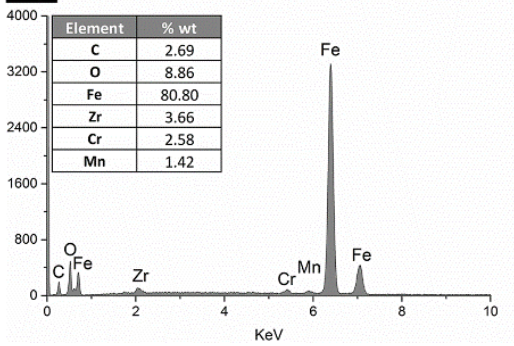

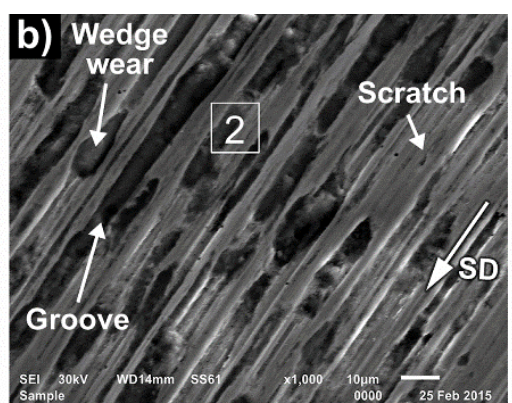

e)

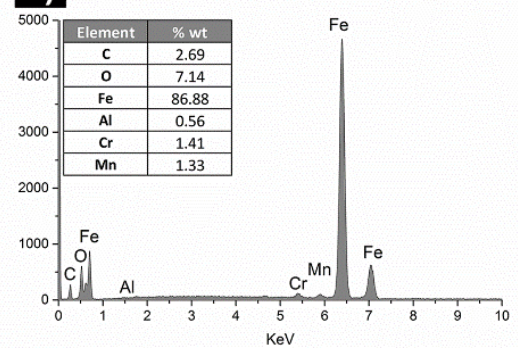

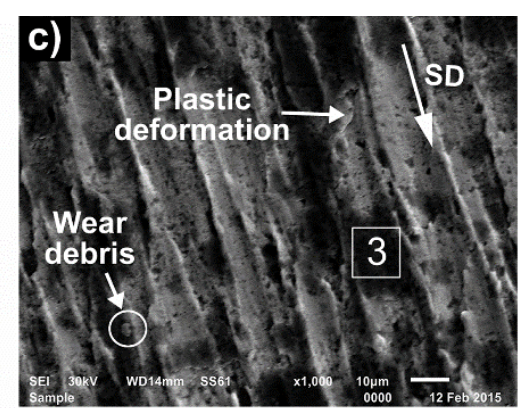
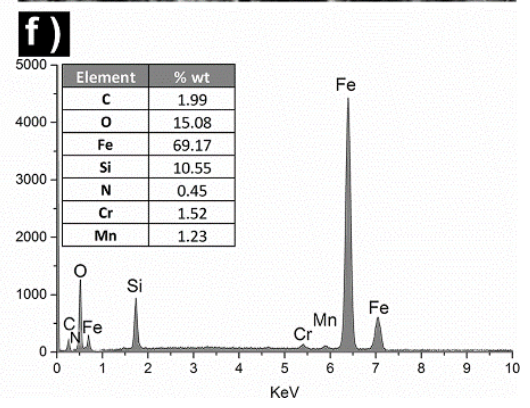

Figure 5. SEM micrographs and EDS spectra analyses of the wear mark on AISI 4140 annealed steel tested in dry conditions with different ceramic counterparts: $\mathrm{ZrO}_{2}(\mathbf{a}, \mathbf{d}), \mathrm{Al}_{2} \mathrm{O}_{3}(\mathbf{b}, \mathbf{e})$, and $\mathrm{Si}_{3} \mathrm{~N}_{4}(\mathbf{c}, \mathbf{f})$. Note: Numbers in SEM micrographs indicate the location for the EDS analyses. SD represents the sliding direction of the friction tests.

Furthermore, the presence of Zirconium in this spectrum suggests that scraps of pin particles that could be detached due to local regions of low strength or due to fatigue stresses were trapped in this area. In contrast, the micrograph of the steel sample tested against $\mathrm{Al}_{2} \mathrm{O}_{3}$ (Figure $5 \mathrm{~b}$ ) showed wedge wear marks and scratches in the sliding direction, both characteristics of abrasive wear. It has been established that there are various degrees 
of abrasive wear of metals [20]. Cutting first appears to generate a long ribbon-like wear scrap due to repeated abrasive contact. Then the material is pushed in front of the grit forming wedges; this grows till its subsequent separation and the process repeats over and over again. Lastly, ploughing wear with no wear particles arises as a stable abrasive state where the material is displaced sideways. This last characteristic was confirmed by the wear profiles in Figure 4e. By analyzing the worn zone marked with number 2 (Figure 5e), a considerable amount of oxygen was observed, which suggests oxidation of the steel. Similarly, a small amount of aluminum can be observed in this region, which could indicate traces of the counterpart material. Regarding the wear of the steel tested against $\mathrm{Si}_{3} \mathrm{~N}_{4}$, a certain degree of adhesive wear is observed in Figure $5 \mathrm{c}$. Plastic deformation can be observed here, but no large bumps of adhering material, as observed against $\mathrm{ZrO}_{2}$. However, abrasive wear traits such as scratches and wear debris were observed. The EDS analysis in point 3 (Figure 5f) also suggests large degradation of the steel by oxidation by indicating a high degree of oxygen content. The presence of silicon could indicate the presence of pin wear particles.

\subsubsection{Wear Behavior}

To quantify the wear suffered by the AISI 4140 annealed steel under the different systems, Figure 6 shows the width of the wear track (a) as well as the wear rate value obtained by profilometry (b) representing the rate at which the material was removed from the original surface. It can be corroborated from Figure 6a that, under all loads, the wear track width was smaller for the AISI 4140 annealed steel samples tested against $\mathrm{ZrO}_{2}$; these values ranged from 132 to $368 \mu \mathrm{m}$, whereas those tested against $\mathrm{Si}_{3} \mathrm{~N}_{4}$ exhibited the widest wear tracks, which varied from 467 to $1002 \mu \mathrm{m}$. As expected, with all the counterparts, an increase in the wear track width was observed with the increase of load. On the other hand, Figure $6 \mathrm{~b}$ shows that the steel samples tested against $\mathrm{ZrO}_{2}$ also showed the lowest wear rate, which was two orders of magnitude lower than the values generated with $\mathrm{Al}_{2} \mathrm{O}_{3}$ and $\mathrm{Si}_{3} \mathrm{~N}_{4}$ at the load of $1.5 \mathrm{~N}$. The highest values were found with the $\mathrm{Al}_{2} \mathrm{O}_{3}$ counterpart because it was the one that generated the deepest wear marks. The wear rate values were in the order of $\times 10^{-6}\left[\mathrm{~mm}^{3} / \mathrm{Nm}\right]$. The samples tested against $\mathrm{Si}_{3} \mathrm{~N}_{4}$ were the only ones that showed a slight, but clear tendency in wear rate, to decrease with the intensity of load, which could be because a more stable state was reached.

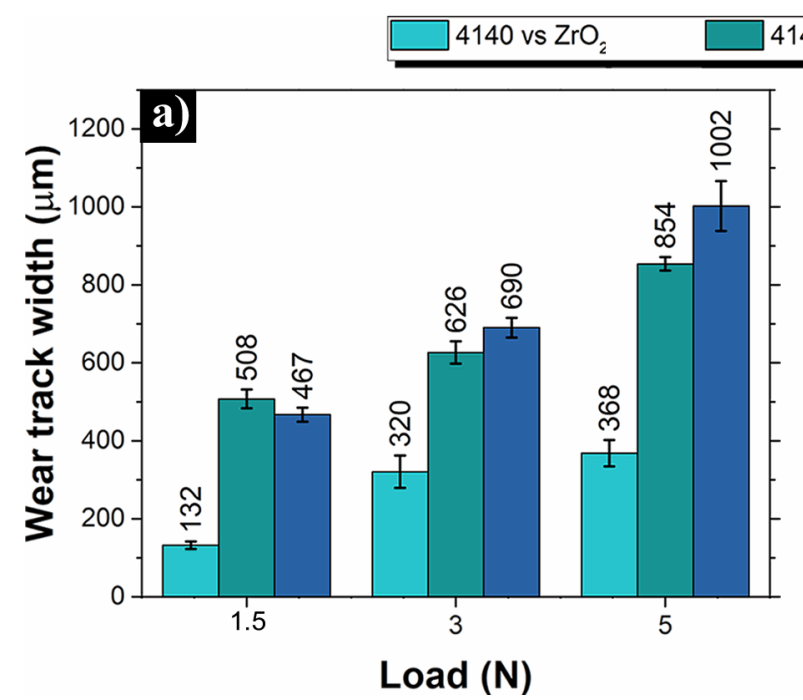
4140 vs $\mathrm{Al}_{2} \mathrm{O}_{3} \quad \square 4140$ vs $\mathrm{Si}_{3} \mathrm{~N}_{4}$

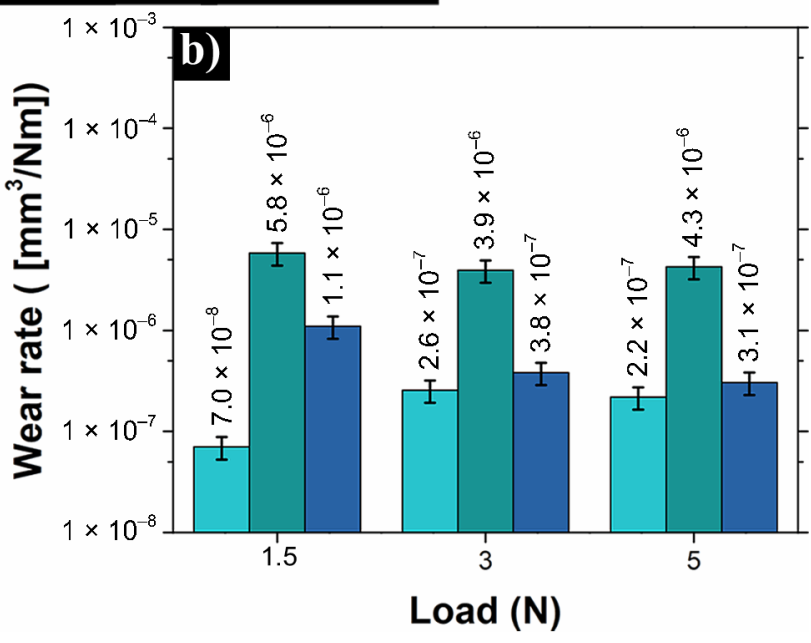

Figure 6. Effect of counterparts and loads on the wear track width (a) and wear rate performance (b) of AISI 4140 annealed steel under dry conditions. 


\subsubsection{Effect on Microhardness Behavior}

To evaluate the effect of the sliding process on the properties of the AISI 4140 annealed steel in the contact surface, the microhardness on the wear track of the steel samples studied under $5 \mathrm{~N}$ was analyzed. Figure 7 shows a representative optical micrograph of a microhardness indentation on the worn surface of a steel sample tested with $\mathrm{ZrO}_{2}$ (a), and the Vickers Microhardness behavior (b) of worn surfaces for each ceramic counterpart at different sliding distances. It can be seen that the microhardness of the worn steel surfaces was affected by the friction and wear processes. Those samples tested against $\mathrm{ZrO}_{2}$ and $\mathrm{Si}_{3} \mathrm{~N}_{4}$, which were essentially worn due to the adhesive mechanism, showed an increase in the hardness of the steel as the sliding distance increased. An increase in hardness of up to $20 \%$ at the end of $1000 \mathrm{~m}$ was achieved concerning the initial hardness of the substrate on both counterparts. Besides, it is important to note that as these samples also exhibited the lowest values of wear rate, it could be implied that the increase in hardness improved the wear resistance of the steel.
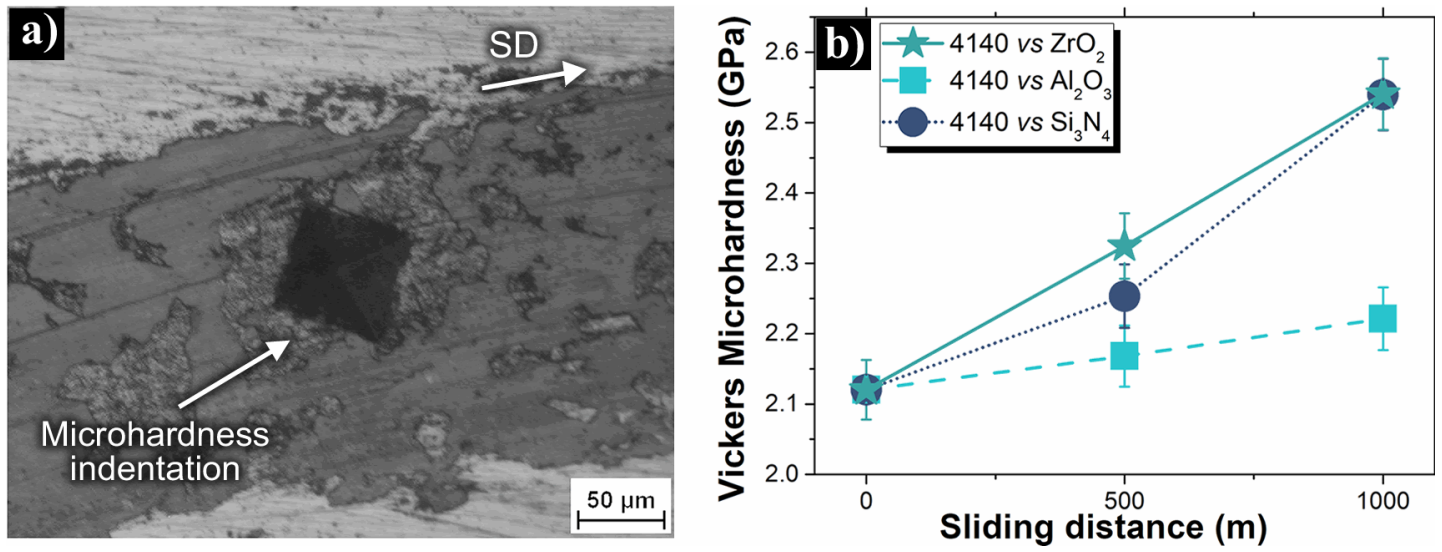

Figure 7. Optical micrograph at 500X showing a microhardness indentation on the steel tested against $\mathrm{ZrO}_{2}$ (a) and $\mathrm{Vickers}$ Microhardness evolution through sliding distance (b). SD represents the sliding direction of the friction tests.

In contrast, those tested against $\mathrm{Al}_{2} \mathrm{O}_{3}$, which suffered abrasive wear, exhibited a slight increase of only $5 \%$ after $1000 \mathrm{~m}$ of sliding. Figure A1 of Appendix A shows the evaluation of microhardness in steel samples tested against $\mathrm{ZrO}_{2}$ but at a greater sliding distance of $2000 \mathrm{~m}$. A limit of this behavior of hardness was exhibited to increase with the sliding distance. This result opens the possibility to further investigate the growth rates in hardness with respect to time/distance, as well as the removal rates of the hardest particles to define the most appropriate conditions for several purposes.

With the goal of identifying the cause of microhardness increments, the steel samples were cut in the transversal direction. They were then polished and chemically etched to observe the microstructure. Figure 8 shows micrographs of the AISI 4140 annealed steel etched surfaces. It can be noted that the microstructure near the worn surfaces of the steel samples tested against $\mathrm{ZrO}_{2}$ and $\mathrm{Si}_{3} \mathrm{~N}_{4}$ revealed a change in the original phases. The Pearlite phase displayed reductions in the grain size as well as in the interlamellar distances between ferrite and cementite constituents. However, the ferritic phase showed only decreases in the grain size. These responses are attributes of strain hardening, which increases the hardness and toughness of metallic materials due to rise in yield stress with the increase of plastic strain [21]. In these cases, the plastic deformations occurred during the sliding friction process. The refinement on worn surfaces tested with $\mathrm{ZrO}_{2}$ and $\mathrm{Si}_{3} \mathrm{~N}_{4}$ was launched to a depth of approximately $50 \mu \mathrm{m}$ (Zone I). After that distance, a transition layer can be observed (Zone II), where the pearlite was not completely refined. In contrast, the sample tested against $\mathrm{Al}_{2} \mathrm{O}_{3}$ did not show a perfect grain refinement near the worn surface. 

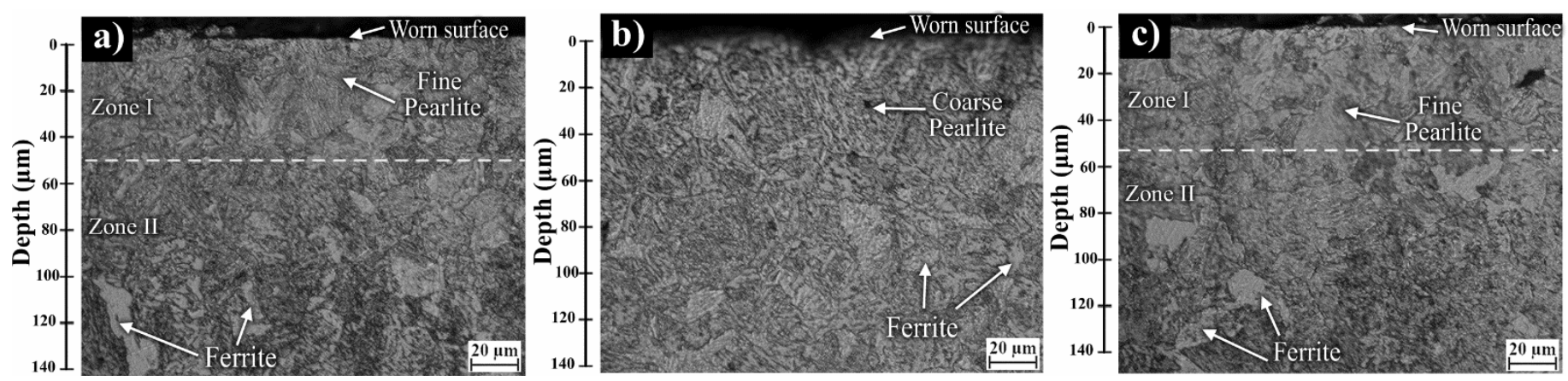

Figure 8. Microstructures at 500X at the transverse section of AISI 4140 annealed steel tested against $\mathrm{ZrO}_{2}(\mathbf{a}), \mathrm{Al}_{2} \mathrm{O}_{3}(\mathbf{b})$, and $\mathrm{Si}_{3} \mathrm{~N}_{4}(\mathbf{c})$. Note: the horizontal dashed line shown in $(\mathbf{a}, \mathbf{c})$ is used to highlight the transition from zone I to zone II.

3.3. Microstructure and Tribological Behavior of Hardened and Tempered AISI 4140 Steel against $\mathrm{ZrO}_{2}$ in Dry Conditions

Figure 9 shows optical micrographs of the microstructure (a) and wear track surface (b) of the hardened and tempered AISI 4140 steel. It can be observed that the microstructure of the steel consists basically of tempered lath martensite, which is characteristic of this thermal treatment. Regarding the worn surface of the steel, the same wear mechanism can be observed, presented by its corresponding characteristics in annealed condition. It comprises adhesive wear in the form of bonded material, combined with abrasive marks. Besides, the hardness values in the worn surface section slightly decreased. Table 4 includes the friction and wear results obtained in this system. Although the hardness value was increased by this thermal treatment, there was a minimal improvement in the tribological properties.
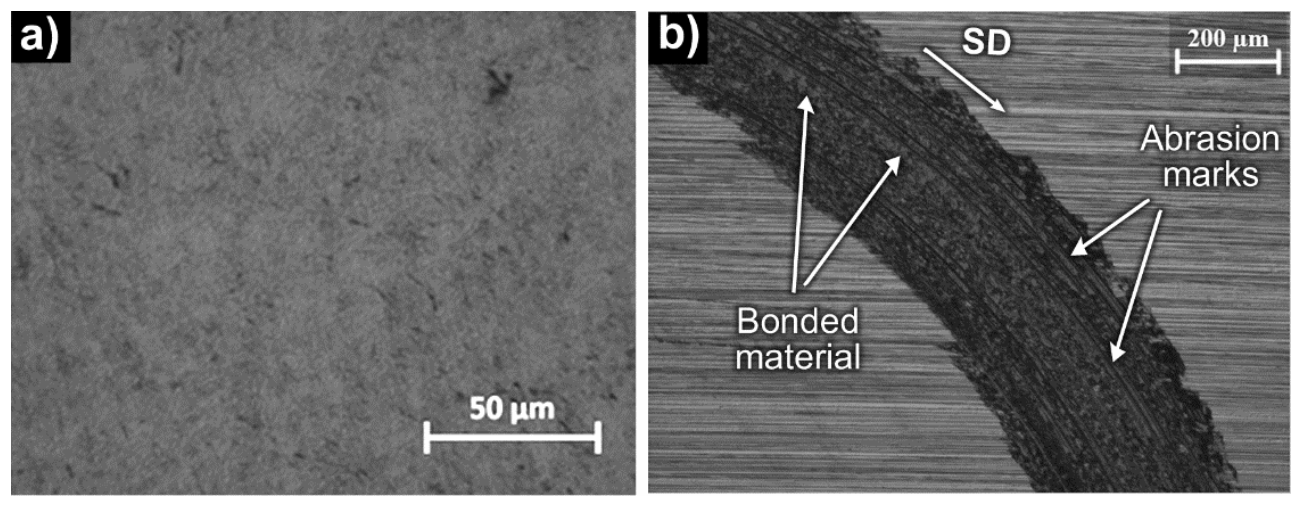

Figure 9. Optical micrographs of the microstructure (a) and worn surface (b) of hardened and tempered AISI 4140 steel. SD represents the sliding direction of the friction tests.

Table 4. Friction and wear results of hardened and tempered AISI 4140 steel vs. $\mathrm{ZrO}_{2}$.

\begin{tabular}{cccccc}
\hline \multicolumn{2}{c}{$\begin{array}{c}\text { Kinetic Friction } \\
\text { Coefficient } \\
\text { Mean }\end{array}$} & Std. Dev. & Mean & Wear Track Width & \multicolumn{2}{c}{ HV in the Worn Surface after } \\
$(\mu \mathrm{m})$ & Std. Dev. & Mean & Std. Dev. \\
\hline 0.47 & 0.04 & 309 & 39 & 4.80 & 0.16 \\
\hline
\end{tabular}

3.4. Tribological Behavior of AISI 4140 Annealed Steel against Ceramics in Lubricated Conditions 3.4.1. Friction Behavior

The effect on the kinetic friction coefficient of AISI 4140 annealed steel by the different ceramic counterparts and normal loads in lubricated conditions is presented in Figure 10. It can be observed that lubrication helped significantly decrease friction. This property 
reached reductions up to $76 \%, 81 \%$, and $88 \%$ in systems tested against $\mathrm{ZrO}_{2}, \mathrm{Al}_{2} \mathrm{O}_{3}$, and $\mathrm{Si}_{3} \mathrm{~N}_{4}$, respectively, in comparison with their correspondents in dry conditions at $1.5 \mathrm{~N}$. Concerning lubrication, the friction coefficient of the steel under almost all counterparts and loads was very low and within a closed range from 0.08 to 0.13 . The highest friction coefficient $\left(\mu_{\mathrm{k}}=0.19\right.$ ) was detected when the steel was tested against $\mathrm{Al}_{2} \mathrm{O}_{3}$ under $5 \mathrm{~N}$, whereas the lowest value $\left(\mu_{\mathrm{k}}=0.08\right)$ was found against $\mathrm{Si}_{3} \mathrm{~N}_{4}$ at the same load. In all systems, a clear tendency was not observed on the friction coefficient with the increase of load. An exception was presented by the $\mathrm{Al}_{2} \mathrm{O}_{3}$ counterpart, which exhibited a clear upward trend.

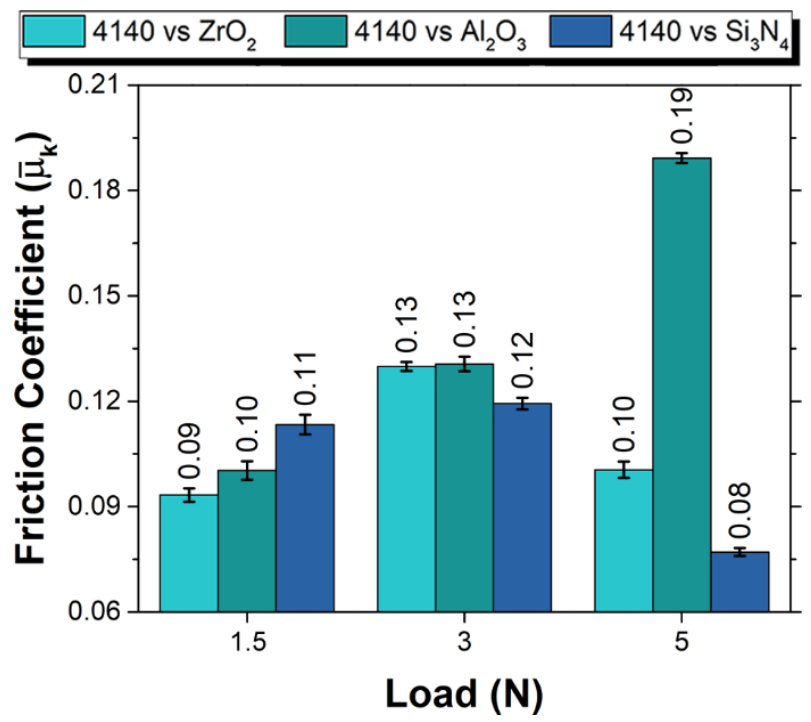

Figure 10. Effect of counterparts and loads on the friction performance of AISI 4140 annealed steel in lubricated conditions.

\subsubsection{Wear Mechanisms}

In lubricated conditions, for each ceramic counterpart, the wear mechanism of the AISI 4140 annealed steel was almost identical in all loads employed. Figure 11 displays characteristic optical micrographs of wear tracks on AISI 4140 annealed steel analyzed at $5 \mathrm{~N}$ as representative samples, and the profiles of worn surfaces at different loads. It can be observed that with the lubricating medium, the wear was considerably decreased. The steel samples tested against $\mathrm{ZrO}_{2}$ (Figure 11a) exhibited slight wear; only some scratches in the sliding direction were seen, typical of incipient abrasive wear. However, such wear could not be observed by profilometry (Figure 11d). On the other hand, the steel samples tested against $\mathrm{Al}_{2} \mathrm{O}_{3}$ and $\mathrm{Si}_{3} \mathrm{~N}_{4}$ exhibited even lesser wear. The wear marks for these samples were barely perceptible by light microscopy (Figure 11 b,c), they looked like shades. Furthermore, in these cases, the depth of the worn indentation could not be detected by profilometry (Figure $11 \mathrm{e}, \mathrm{f}$ ) but could suggest that the wear mechanism was a light polishing. In Figure S2 in the Supplementary Materials file, optical micrographs of AISI 4140 annealed steel worn surfaces in lubricated conditions at all loads can be observed.

\subsubsection{Wear Behavior}

Since the wear suffered by the AISI 4140 annealed steel in lubricated conditions was only perceived by optical microscopy, Figure 12 presents the width of the wear tracks as a particular method to measure wear. Under lubricated conditions, the wear track width values obtained with the different counterparts were up to 12 times smaller than their equivalent dry values. At loads of 1.5 and $3 \mathrm{~N}$ with lubrication, the widest wear tracks were obtained with the $\mathrm{ZrO}_{2}$ counterpart, while the smallest were presented when the steel was tested against $\mathrm{Al}_{2} \mathrm{O}_{3}$. However, at the $5 \mathrm{~N}$ load, the roles were inverted, and the samples tested against $\mathrm{Al}_{2} \mathrm{O}_{3}$ showed 
the highest values. Again, it was observed that, for each counterpart, there was a well-defined tendency in the wear track width to increase as the load increases.
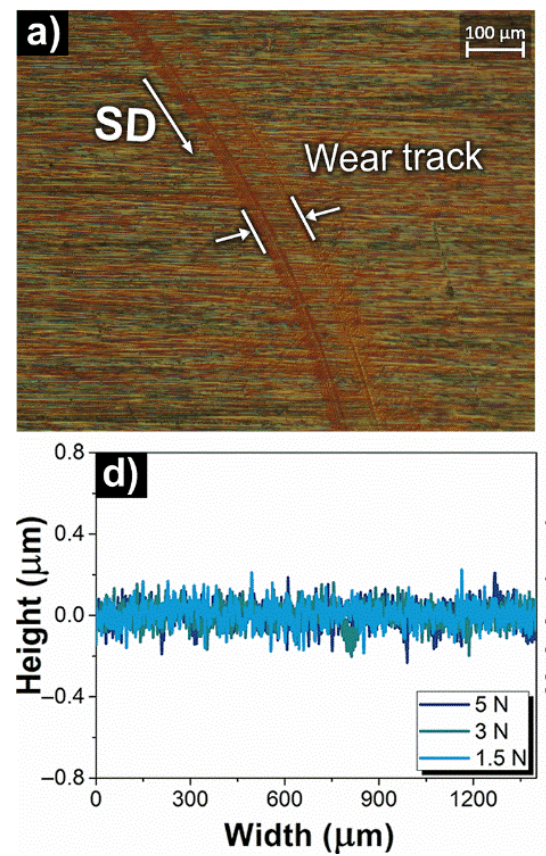

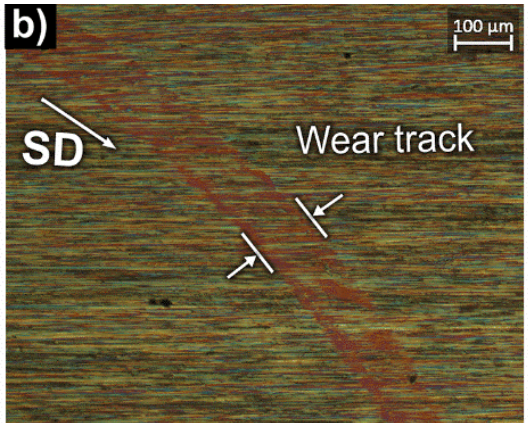

${ }^{0.8} \mathbf{e )}$

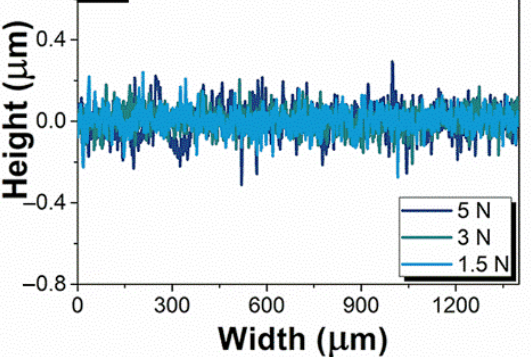

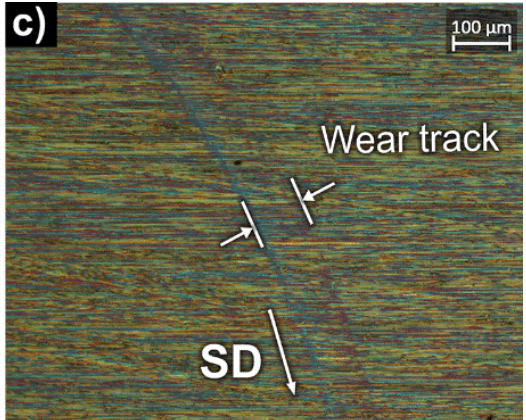

${ }^{0.8} \mathbf{\text { f) }}$

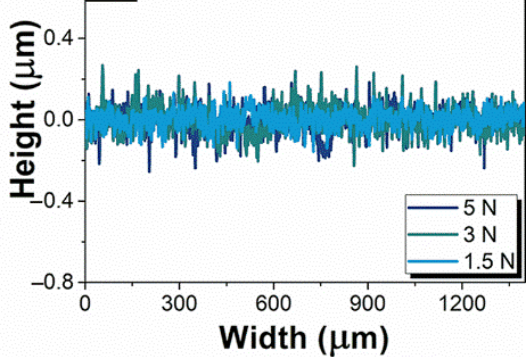

Figure 11. Optical micrographs and profiles of the wear mark on AISI 4140 annealed steel tested in lubricated conditions with different ceramic counterparts: $\mathrm{ZrO}_{2}(\mathbf{a}, \mathbf{d}), \mathrm{Al}_{2} \mathrm{O}_{3}(\mathbf{b}, \mathbf{e})$, and $\mathrm{Si}_{3} \mathrm{~N}_{4}(\mathbf{c}, \mathbf{f})$. Note: The optical micrographs were taken at 100X with a polarizing filter and correspond to the load of $5 \mathrm{~N}$ as representative samples. SD represents the sliding direction of the friction tests.

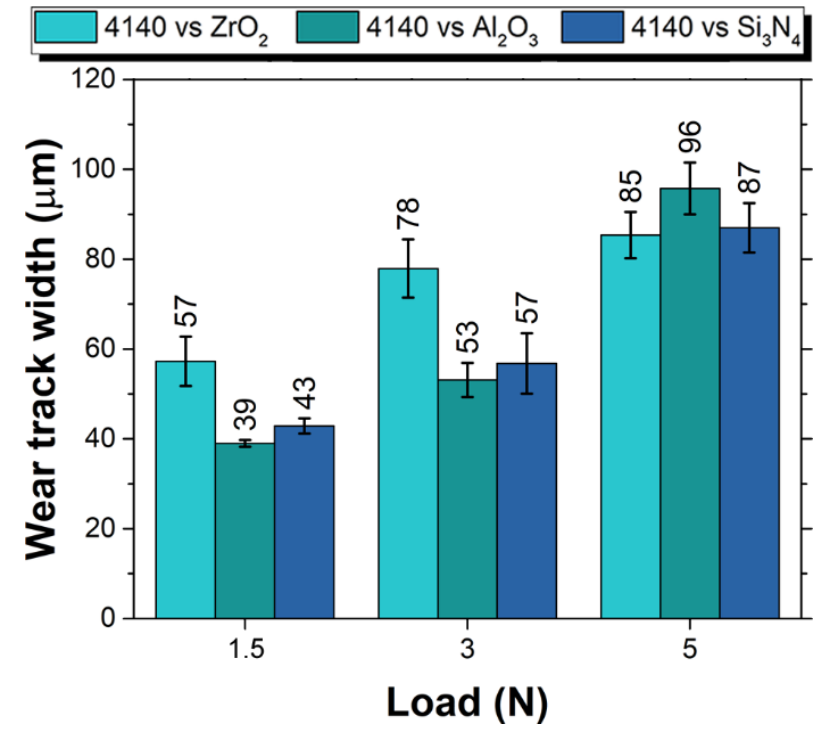

Figure 12. Effect of counterparts and loads on the wear track width of AISI 4140 annealed steel under lubricated conditions.

\subsubsection{Lubricating Regimes}

Table 5 summarized the estimated central and minimum lubricant film thicknesses and lambda ratio values for the lubricated systems of AISI 4140 annealed steel and the different counterparts. With all counterparts, the central and minimum lubricant film thicknesses decreased with the increasing of normal load but were within a close range from 168 to $153 \mathrm{~nm}$, and from 94 to $84 \mathrm{~nm}$, respectively, while the lambda ratio varied 
from 3.4 to 3.1, and 1.9 to 1.7 for central and minimum values. Those dates correspond to hydrodynamic and mixed lubrication, which are regimes in which a considerable thick lubricating film separates the surfaces in contact and reduces wear. The highest values were obtained with the $\mathrm{ZrO}_{2}$ counterpart, but against $\mathrm{Al}_{2} \mathrm{O}_{3}$ and $\mathrm{Si}_{3} \mathrm{~N}_{4}$, the lubricating film thickness and the lambda ratio were estimated to be equal.

Table 5. Lubricant film thickness (h) and lambda ratio ( $\lambda$ ) of AISI 4140 annealed steel lubricated systems.

\begin{tabular}{ccccccc}
\hline Counterpart & Load & $\mathbf{c}$ & $\mathbf{H}$ & $\mathbf{m i n}$ & $\mathbf{C}$ & $\boldsymbol{\lambda}$ \\
& $\mathbf{N}$ & $\mathbf{n m}$ & $\mathbf{n m}$ & $\mathbf{N m}$ & $\begin{array}{c}\text { min } \\
\mathbf{n m}\end{array}$ \\
\hline \multirow{2}{*}{$\mathrm{ZrO}_{2}$} & 1.5 & 168 & 94 & 3.4 & 1.9 \\
& 3 & 160 & 89 & 3.2 & 1.8 \\
$\mathrm{Al}_{2} \mathrm{O}_{3}$ & 5 & 155 & 86 & 3.1 & 1.7 \\
& 1.5 & 166 & 92 & 3.3 & 1.8 \\
$\mathrm{Si}_{3} \mathrm{~N}_{4}$ & 3 & 158 & 87 & 3.2 & 1.7 \\
& 1.5 & 153 & 84 & 3.1 & 1.7 \\
& 3 & 166 & 92 & 3.3 & 1.8 \\
& 5 & 158 & 87 & 3.2 & 1.7 \\
\hline
\end{tabular}

\section{Discussion}

Friction and wear phenomena are important problems to reduce to achieve better efficiencies in machines and mechanical elements, as well as to decrease damage and costs due to material loss. However, they are also quite complex, since they depend on many variables such as the properties of the materials in contact, loads and speeds, and environmental conditions, among others. In this study, it was seen how, under the same conditions, three different ceramic counterparts can produce quite a different effect on the widely used AISI 4140 annealed steel, mainly in non-lubricated conditions. In this state, the counterpart $\mathrm{ZrO}_{2}$, due to its lower modulus of elasticity and Poisson's ratio, produced lower contact pressure and therefore significantly decreased friction. This condition was repeated with the other two counterparts, where the $\mathrm{Si}_{3} \mathrm{~N}_{4}$ counterpart produced greater friction. Wear behavior was a bit different. Here, the hardness and toughness of the counterparts could have a greater influence. In this case, $\mathrm{Al}_{2} \mathrm{O}_{3}$, which is the counterpart with higher hardness and lower toughness, caused more damage to the steel. The second harder counterpart, $\mathrm{Si}_{3} \mathrm{~N}_{4}$, although with higher toughness, produced middle wear. In that sense, $\mathrm{ZrO}_{2}$, which has the lowest hardness and intermediate toughness, caused the least wear on the steel. On the other hand, the distinct counterparts had different effects on the wear mechanisms. However, for the same counterpart, wear mechanisms exhibited were the same in each load, and only the intensity of them varied. Steel samples tested against $\mathrm{Al}_{2} \mathrm{O}_{3}$ were abraded mainly because of the high hardness of the counterpart, while those tested against $\mathrm{ZrO}_{2}$ and $\mathrm{Si}_{3} \mathrm{~N}_{4}$, which had a lower hardness, were worn by adhesion. Such a mechanism produces large plastic deformations, and as observed, they also produced a change in the microstructure of the material near the wear zone. The coarse pearlite on the original surface underwent refinement and became fine pearlite. This fine phase had higher strength and toughness because finer layers resist relative sliding to each other. Thus, the steel becomes harder, and its wear resistance is improved. Under lubricated conditions, behavior is largely defined by the thickness of the lubricant that separates the contact surfaces, as well as the physical-chemical interaction between the surfaces and the lubricating medium. In this study, it was observed that, under mixed or hydrodynamic conditions, both friction and wear of AISI 4140 annealed steel were considerably reduced. Generally, the higher the lubricating film thickness, the lower the wear. This was confirmed by this study, since all the counterparts obtained lower wear at a load of $1.5 \mathrm{~N}$, where they allowed a higher film thickness. On the other hand, friction does not have a linear relationship with film thickness, as can be seen in the well-known Stribeck diagram [19]. 
Such curves must be generated for each system by varying loads, speeds, and viscosities, which is out of the aim of this investigation.

Interestingly, there is enough evidence that the friction and wear properties of the AISI 4140 annealed steel against ceramic counterparts are in the range of those reported for the same steel treated with different techniques at similar dry friction conditions. By comparing the tribological performance of this steel against $\mathrm{ZrO}_{2}$, it was observed to be closed to that of the hardened and tempered steel at the same conditions (at $5 \mathrm{~N}$ ), as was exhibited in Section 3.3. Although the hardening treatment increased the hardness of the steel by more than $144 \%$ compared to simple annealing conditions, friction and wear were only improved by $14 \%$ and $16 \%$, respectively. Furthermore, the presented results with the annealed steel are also within the values reported by other authors. For example, Totik et al. [4] reported friction coefficient values ranging from $\mu=0.76$ to $\mu=0.41$ for a 4140-steel hardened by induction. Similarly, M. Heydarzadeh Sohi et al. [22] described friction coefficient values around $\mu=0.8$ to $\mu=1.1$ for plasma nitrocarburized AISI 4140 steel. They applied lower contact pressure than those used in the present work. In addition, C. Lorenzo-Martin and O.O. Ajayi [23] found friction coefficients of $\mu=0.78$ and $\mu=0.6$ for AISI 4140 steel hardened by friction stir process (FSP) and conventional heat treatment (HT), respectively, both with a lower contact pressure $(0.7 \mathrm{GPa})$ than this work. Although for the lubricated condition they used contact pressures slightly higher than those used in the present investigation, they reported higher friction coefficient values than those between $\mu=0.1$ and $\mu=1.2$ for all the friction tests. As a final point, the tribosystems studied in this work produced wear rates of about $10^{-8}$ to $10^{-6} \mathrm{~mm}^{3} / \mathrm{Nm}$ in dry conditions and much lower in lubricated conditions, which represent systems with good wear behavior [24].

\section{Conclusions}

In this contribution, the tribological behavior of the AISI 4140 steel in annealed condition was investigated against three different ceramic counterparts: $\mathrm{ZrO}_{2}, \mathrm{Al}_{2} \mathrm{O}_{3}$, and $\mathrm{Si}_{3} \mathrm{~N}_{4}$ with and without lubrication.

In dry conditions, the $\mathrm{ZrO}_{2}$ counterpart allowed to obtain the lowest friction and wear at all tested loads. Notably, at $1.5 \mathrm{~N}$, friction coefficient and wear rate were reduced $60 \%$ and $94 \%$, respecting $\mathrm{Si}_{3} \mathrm{~N}_{4}$ counterpart, respectively, and up to $30 \%$ and $99 \%$ regarding $\mathrm{Al}_{2} \mathrm{O}_{3}$. The wear mechanisms did not depend on the normal load, but on the counterpart employed. The steel samples tested against $\mathrm{Al}_{2} \mathrm{O}_{3}$ were worn out by abrasion due to the high hardness of the pin, whereas the samples tested against $\mathrm{ZrO}_{2}$ and $\mathrm{Si}_{3} \mathrm{~N}_{4}$ allowed adhesive mechanism. The plastic deformation of the steel samples experimented with the latter counterparts caused grain refinement near the worn surface by strain hardening, thus improving the mechanical properties and wear resistance.

In lubricated conditions, all counterparts caused low friction and wear due to the mixed and hydrodynamic lubricating regimes. Compared with $\mathrm{ZrO}_{2}$ at $5 \mathrm{~N}, \mathrm{Si}_{3} \mathrm{~N}_{4}$ counterpart decreased friction and wear $60 \%$ and $9 \%$, respectively, whereas $\mathrm{Al}_{2} \mathrm{O}_{3}$ exhibited reductions of $47 \%$ and $11 \%$.

For the above, this study suggests that AISI 4140 annealed steel can be employed in mechanical systems in contact with ceramic counterparts such as in hybrid bearing applications and produced acceptable friction and wear. Likewise, it encourages the use of these materials in a greater range of tribological applications, even without the implementation of other treatment processes.

Supplementary Materials: The following are available online at https: / www.mdpi.com/article/ $10.3390 /$ met11081275/s1, Figure S1. Optical micrographs at 100X of the wear track on AISI 4140 steel tested in dry conditions with different ceramic counterparts and loads. Figure S2. Optical micrographs at 128X of the wear track on AISI 4140 steel tested in lubricated conditions with different ceramic counterparts and loads.

Author Contributions: Conceptualization, J.S.G.-M. and K.J.M.; methodology, M.T.H.-S. and L.D.A.C.; validation, J.S.G.-M. and K.J.M.; formal analysis, M.T.H.-S., L.D.A.-C., J.S.G.-M. and K.J.M.; 
writing—original draft preparation, M.T.H.-S.; writing—review and editing, M.T.H.-S. and K.J.M.; supervision, K.J.M. All authors have read and agreed to the published version of the manuscript.

Funding: This research received no external funding.

Data Availability Statement: All data presented in this study are available on request from the authors.

Acknowledgments: The authors profoundly appreciate the support of the National Technology of Mexico in Celaya (TecNM). M.T.H.-S. thanks Consejo Nacional de Ciencia y Tecnología (CONACYT) in Mexico for the scholarships awarded to carry out this study.

Conflicts of Interest: The authors declare no conflict of interest.

\section{Appendix A}

In order to evaluate the microhardness behavior on the worn surface of 4140 annealed steel, additional essays were done with the counterpart of $\mathrm{ZrO} 2$ under the same tribological conditions at a load of 5 N, but at 2000 m of sliding distance; see Figure A1. In this figure, it can be seen that as the sliding distance increases above $1000 \mathrm{~m}$, the hardness in the wear track slightly decreases. This may be because as harder wear particles are created, it is easier for them to be removed from the original surface. Further studies will be carried out on the hardness behavior for time/distance with the focus of specifying the most proper conditions for specific purposes.

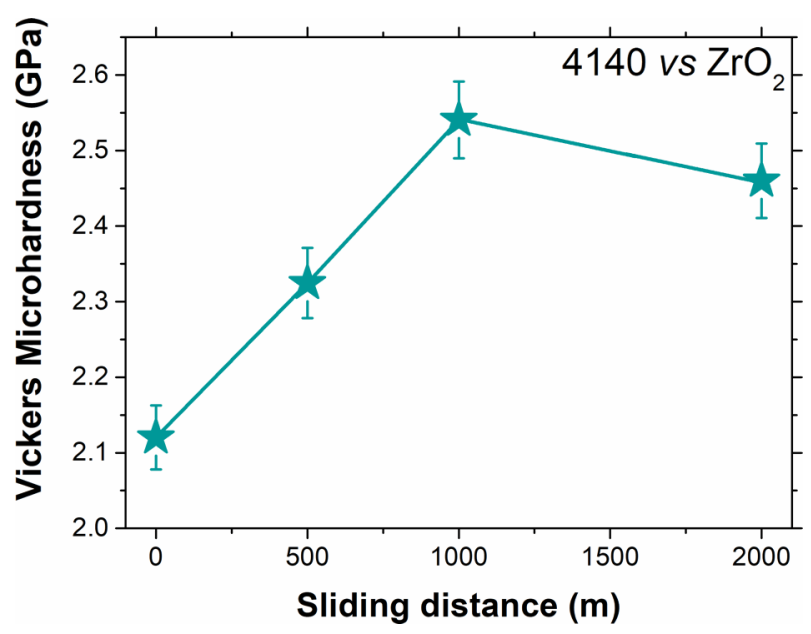

Figure A1. Vickers Microhardness on the worn surface of AISI 4140 annealed steel at different sliding distances.

\section{References}

1. Ulutan, M.; Celik, O.N.; Gasan, H.; Er, Ü. Effect of Different Surface Treatment Methods on the Friction and Wear Behavior of AISI 4140 Steel. J. Mater. Sci. Technol. 2010, 26, 251-257. [CrossRef]

2. $\quad$ Singh, H.; Singla, Y.K.; Singh, A.K.; Chattopadhayay, K. Effect of Nanofly Ash as Lubricant Additive on the Tribological Properties of SAE 10W-30 Oil: A Novel Finding. Trans. Indian Inst. Met. 2020, 73, 1-5. [CrossRef]

3. Hafeez, M.A.; Farooq, A. Effect of Heat Treatments on the Mechanical and Electrochemical Corrosion Behavior of 38CrSi and AISI 4140 Steels. Met. Microstruct. Anal. 2019, 8, 479-487. [CrossRef]

4. Totik, Y.; Sadeler, R.; Altun, H.; Gavgali, M. The effects of induction hardening on wear properties of AISI 4140 steel in dry sliding conditions. Mater. Des. 2003, 24, 25-30. [CrossRef]

5. Meysami, A.; Ghasemzadeh, R.; Seyedein, S.; Aboutalebi, M. An investigation on the microstructure and mechanical properties of direct-quenched and tempered AISI 4140 steel. Mater. Des. 2010, 31, 1570-1575. [CrossRef]

6. Das, S.R.; Dhupal, D.; Kumar, A. Experimental investigation into machinability of hardened AISI 4140 steel using TiN coated ceramic tool. Measurement 2015, 62, 108-126. [CrossRef]

7. Badaruddin, M.; Wardono, H.; Wang, C.J.; Rivai, A.K. Improvement of low-cycle fatigue resistance in AISI 4140 steel by annealing treatment. Int. J. Fatigue 2019, 125, 406-417. [CrossRef]

8. Sharma, S.; Kini, V. Effect of heat treatment and mechanical characterization of AISI 4140 steel. IJMPERD 2018, 8, 603-610. 
9. Wang, C.; Ye, Y.; Guan, X.; Hu, J.; Wang, Y.; Li, J. An analysis of tribological performance on Cr/GLC film coupling with Si3N4, $\mathrm{SiC}, \mathrm{WC}, \mathrm{Al} 2 \mathrm{O} 3$ and $\mathrm{ZrO} 2$ in seawater. Tribol. Int. 2016, 96, 77-86. [CrossRef]

10. Xu, S.; Xu, Y.; Liu, Y.; Fang, M.; Wu, X.; Min, X.; Zhang, X.; Huang, Z. Fabrication and abrasive wear behaviour of Zr-SiC-Al2O3 ceramic. Ceram. Int. 2017, 43, 15060-15067. [CrossRef]

11. Liu, C.; Sun, J. Effect of load on friction and wear behaviors of alumina matrix ceramic guideway materials. J. Alloy. Compd. 2018, 743, 268-273. [CrossRef]

12. Yan, S.; Wei, C.; Zou, H.; Chen, J.; Li, Y.; Shen, T.; Wang, A.; Sui, T.; Lin, B. Fabrication and tribological characterization of laser textured engineering ceramics: Si3N4, SiC and ZrO2. Ceram. Int. 2021, 47, 13789-13805. [CrossRef]

13. Rowthu, S.; Deshpande, P.; Annamalai, A.; Hoffmann, P. Harnessing nano oil reservoir network for generating low friction and wear in self-mating alumina. Mater. Des. 2021, 206, 109821. [CrossRef]

14. Stachowiak, G.W.; Batchelor, A.W. Wear of Non-Metallic Materials. In Engineering Tribology, 4th ed.; Stachowiak, G.W., Batchelor, A.W., Eds.; Butterworth-Heinemann: Waltham, MA, USA, 2014; pp. 679-734.

15. Hernández-Sierra, M.T.; Aguilera-Camacho, L.D.; Báez-García, J.E.; García-Miranda, J.S.; Moreno, K.J. Thermal Stability and Lubrication Properties of Biodegradable Castor Oil on AISI 4140 Steel. Metals 2018, 8, 428. [CrossRef]

16. ASTM. Standard G 99-05. Standard Test Method for Wear Testing with a Pin-on-Disk Apparatus. ASTM Int. 2005, 1-5.

17. Hamrock, B.J.; Dowson, D. Isothermal Elastohydrodynamic Lubrication of Point Contacts: Part 111-FullyFlooded Results. J. Lubr. Technol. 1977, 99, 264-275. [CrossRef]

18. Hernández-Sierra, M.T.; Bravo-Sánchez, M.G.; Báez, J.E.; Aguilera-Camacho, L.D.; García-Miranda, J.S.; Moreno, K.J. Improvement Effect of Green Lubricants on the Tribological and Mechanical Performance of 4140 Steel. Appl. Sci. 2019, 9, 4896. [CrossRef]

19. Abdelbary, A. Extreme Tribology: Fundamentals and Challenges, 1st ed.; Abdelbary, A., Ed.; CRC Press: Boca Raton, FL, USA, 2020; pp. 73-140.

20. Kato, K. Classification of wear mechanisms/models. Proc. Inst. Mech. Eng. Part J. J. Eng. Tribol. 2002, 216, 349-355. [CrossRef]

21. Rojacz, H.; Mozdzen, G.; Weigel, F.; Varga, M. Microstructural changes and strain hardening effects in abrasive contacts at different relative velocities and temperatures. Mater. Charact. 2016, 118, 370-381. [CrossRef]

22. Sohi, M.H.; Ebrahimi, M.; Raouf, A.H.; Mahbouibi, F. Effect of plasma nitrocarburizing tempertaure on the wear behavior of AISI 4140 Seel. Surf. Coat. Tech. 2010, 205, 584-589.

23. Lorenzo-Martin, C.; Ajayi, O.O. Rapid surface hardening and enhanced tribological performance of 4140 steel by friction stir processing. Wear 2015, 332-333, 962-970. [CrossRef]

24. Stachowiak, G.W.; Batchelor, A.W. Fundamentals of Contact Between Solids. In Engineering Tribology, 4th ed.; Stachowiak, G.W., Batchelor, A.W., Eds.; Butterworth-Heinemann: Waltham, MA, USA, 2014; pp. 475-524. 